| Peran LSM dalam Pendampingan PSK

\title{
PERAN LSM KUSUMA BUANA DALAM PENDAMPINGAN PSK DI DESA BONGAS, INDRAMAYU, JAWA BARAT
}

\section{Erllyn Nurdiansyah ${ }^{1}$}

\begin{abstract}
s
LSM Kusuma Buana is one of social institution which focus with countermeasures on sex worker problem in Bongas Vilage, Indramayu, Jawa Barat. The purpose of LSM Kusuma Buana to be effort autonomous for PSK. Purpose of this reseacrh are: 1). To description profil of LSM Kusuma Buana as social institution to handle PSK problem. 2). To description character of LSM Kusuma Buana to handle PSK problem in Bongas, Indramayu, Jawa Barat.

This research uses kualitatif research methods. Were used primary and secondary data sources. Technique obtained in this research is descriptive analysis that is the data which obtained in this research presented the analyzed descriptively to get an idea about the facts. Information obtained by using purposive sampling tecnique, that is sampling based on speatic objectives. Informats in this study is the LSM Kusuma Buana, prostitutes and former prostitutes. Data was collected by interview methocl, passive participant observation, documentation and literature studies. To examine the validity of this data source using triangulation techniques source and methods. Techniques which used in analyzing the data is data colection, data reduktion, data presentation, and conclusion.

The result showed that: 1). LSM Kusuma Buana as social institusion is the first in Bongas Vilage in assitance prostitutes. 2). The role of LSM Kusuma Buana or Kusuma Bongas as home and friend for sex worker, besides its role as facilitator and catalyst, coach and education, as well as colector of capital. 3). Assistance by LSM Kusuma Buana formed a working group named Kusuma Bongas to empower sex worker by providing mentoring programs, such as community empowerment in the form of revolving capital and education about the worse effect of prostitutions and AIDS, health service and skills activties. Form of empowerement that was given to comecrial sex worker and sex worker make increasingly independent and empowered. 4). Empowerment was given to the prostitutes greated positively by them, because the program can empower prostitutes in Bongas Vilage, Indramayu, Jawa barat.
\end{abstract}

Key words: role of social institutional, assistance program, empowerement

\footnotetext{
${ }^{1}$ Alumni Pendidikan Sosiologi FIS UNY
} 


\section{A. Pendahuluan}

Pekerja Seks Komersial (PSK) sudah cukup menjamur pada kotakota besar di Indonesia, seprti Jakarta, Bandung, Denpasar, Medan dan Batam, bahkan di daerahdaerah yang kecil salah satunya di Indramayu. Indramayu adalah salah satu kabupaten yang terletak di Pesisir Utara Jawa Barat, selain itu juga berada pada jalur Pantura. Mata pencaharian dari penduduk Indramayu sebagian besar adalah buruh tani dan nelayan karena Indramayu di kenal sebagai "Lumbung Padi", mengingat $58,27 \%$ dari luas wilayahnya merupakan areal persawahan, dikenal juga sebagai produsen ikan laut karena dari seluruh produksi ikan laut Jawa Barat sepertinya berasal dari Indramayu ${ }^{2}$. Masalah yang ada di Desa Bongas adalah yang sangat memprihatinkan karena yang dijadikan Pekerja Seks Komersial (PSK) adalah anak-anak di bawah umur usia 12-17 tahun. Data yang diperoleh LSM Kusuma Buana mengenai prostitusi anak di bawah umur di Desa Bongas sudah sejak tahun 1990 dan banyak dilibatkan dalam prostitusi dikarenakan salah satu penyebabnya yaitu anak perempuan putus sekolah, Drop Out (DO) dan tidak melanjutkan ke SLTP, sehingga memudahkan orangtua

\footnotetext{
${ }^{2}$ Kantor Kebudayaan dan Pariwisata Kabupaten Indramayu, Kata Kunci: Sekilas Kota Indramayu, 2008, Tersedia pada http://www.indramayucity.co.cc/index.php? $\mathrm{p}=1$ 5 Sekilas-Kota-Indramayu. 21 Maret 2010. Pukul 11. 40 WIB.
}

atau keluarga dan pihak germo ${ }^{3}$ mendorong anak-anak tersebut bekerja sebagai PSK. Ini merupakan suatu masalah sosial yang menyangkut nilai-nilai sosial dan moral. Masalah tersebut merupakan persoalan, karena menyangkut tata kelakuan yang immoral, berlawanan dengan hukum dan bersifat merusak ${ }^{4}$.

Faktor-faktor

yang mempengaruhi prostitusi anak dibawah umur di Desa Bongas adalah faktor ekonomi, budaya, pendidikan dan pergaulan. Pertama faktor ekonomi yang menjadi alasan karena banyak penduduk di Desa Bongas mata pencahariannya sebagai petani dan buruh tani. Kedua faktor budaya, karena banyak dari orang tua di Desa Bongas lebih memilih anaknya untuk menjadi PSK, karena dianggap lebih mudah dalam mendapatkan uang dan mendapat status sosial dalam masyarakat. Ketiga faktor pendidikan, banyak dari orangtua atau anaknya hanya tamatan SD, ini merupakan kesempatan besar para germo untuk merayu orangtua agar anaknya bisa bekerja sebagai PSK. Keempat faktor pergaulan, anak-anak gadis yang menjadi PSK karena salah pergulan, yang melatarbelakangi faktor ini adalah anak-anak gadis meniru teman-temannya yang bekerja menjadi PSK. ${ }^{5}$

\footnotetext{
${ }^{3}$ Germo: pemburu/induk semang/mucikari bagi perempuan pelacur.

${ }^{4}$ Soerjono Soekanto, Sosiologi Suatu Pengantar, Jakarta: PT Raja Grafindo Persada, 2005, hlm. 375.

${ }^{5}$ Wawancara dengan Pengurus LSM Kusuma Bongas Bpk. NT pada tanggal 2 Februari 2011
} 
Peran LSM dalam Pendampingan PSK

Menurut hasil penelitian yang dilakukan oleh tim fasilitator binaan LSM Kusuma Buana ada tujuh desa di Kecamatan Bongas yang warganya berprofesi sebagai PSK, antara lain Desa Cipaat, Desa Margamulya, Desa Cipedang, Desa Plawangan dan Desa Kertamulya menduduki angka di bawah 50 orang warganya berprofesi sebagai PSK, sedangkan di Desa Bongas jumlah PSK mencapai angka 50 orang yang berprofesi sebagai PSK, serta di Desa Kertajaya mempunyai warganya yang berprofesi sebagai PSK hampir 100 orang. Banyaknya PSK di Kecamatan Bongas dikarenakan ketidakmampuan sistem pendidikan yang ada dan orangtua yang tidak mampu untuk mempertahankan anak mereka agar tidak putus sekolah dan melanjutkan ke jenjang yang lebih tinggi, alasan yang mendasar adalah karena faktor ekonomi. ${ }^{6}$

Berdasarkan latar belakang masalah di atas maka peneliti tertarik untuk mengadakan penelitian tentang Pendampingan PSK dan mantan PSK di Daerah Indramayu khususnya di Desa Bongas Melalui peran LSM Kusuma Buana. Peneliti melakukan penelitian ini agar mendapatkan data yang akurat dan sesuai dengan apa yang akan diteliti oleh peneliti. Hasil yang diperoleh berupa

pukul 13.00 WIB di kantor LSM Kusuma Bongas.

6 Wawancara dengan pengurus LSM Kusuma Bongas Bpk. NT pada tanggal 2 Februari 2011 puku; 13.00 WIB di kantor LSM Kusuma Bongas. pembahasan mengenai peran LSM Kusuma Buana dalam pendampingan PSK di Desa Bongas.

\section{B. Profil LSM Kusuma Buana}

1. Letak dan Keadaan LSM Kusuma Buana

Desa Bongas merupakan desa agraris, karena sebagian besar lahannya adalah persawahan. Sawah irigasi teknis $505 \mathrm{Ha}$, sedangkan permukiman $118 \mathrm{Ha}$. Luas wilayah Desa Bongas $623 \mathrm{Ha}$. Tipologi Desa Bongas adalah desa pantai atau pesisir. Bentang wilayah Desa Bongas datar. Desa Bongas juga di kelilingi oleh 3 sungai, yaitu: Sungai Wanguk, Dampyang Markinah, dan Sungai Beji. Desa Bongas terletak di tengah-tengah desa, yaitu: ${ }^{7}$

$\begin{array}{llr}\text { Utara } & : & \text { Desa } \\ \text { Kertamulya } & & \\ \text { Timur } & \text { : Desa Kertajaya } \\ \text { Selatan } & : & \text { Desa } \\ \text { Sidamulya } & & \\ \text { Barat } & \text { : Desa Cipaat } \\ \text { Jumlah penduduk } & \text { Desa } \\ \text { Bongas } & & \\ \text { Jumlah penduduk } & \text { Desa }\end{array}$
Bongas dirinci menurut pekerjaan sebagai berikut :

\footnotetext{
Pemerintahan Kabupaten Indramayu, Surat Mentri Dalam Negeri Rebuplik Indonesia No. 414.3/316/PMD Tanggal 17 Februari 2003 Tentang Sistem Pendataan Profil Desa dan Profil Kelurahan, Diperbanyak oleh: Pemerintah Kabupaten Indramayu Dinas Koperasi dan Pemberdayaan Masyarakat 2006.
} 
Tabel 1.

Jumlah Penduduk Menurut Pekerjaan

\begin{tabular}{|c|c|c|}
\hline No & Jenis Pekerjaan & Jumlah \\
\hline 1. & PNS & 24 orang \\
\hline 2. & TNI/POLRI & 8 orang \\
\hline 3. & PENSIUNAN & 13 orang \\
\hline 4. & INDUSTRI KECIL & - \\
\hline 5. & PEDAGANG & 427 orang \\
\hline 6. & NELAYAN & 1,236 orang \\
\hline 7. & PETANI & 1,610 orang \\
\hline 8. & BURUH & 951 orang \\
\hline 9. & PELAJAR & 23 orang \\
\hline 10. & MAHASISWA & 747 orang \\
\hline 11. & LAIN-LAIN & 498 orang \\
\hline 12. & BELUM BEKERJA & 5,929 orang \\
\hline & JUMLAH & D \\
\hline
\end{tabular}

(Arsip : Data Kependudukan Berdasarkan Pekerjaan, Desa Bongas Kecamatan Bongas Kabupaten Indramayu)

Berdasarkan tabel di atas dapat disimpulkan bahwa jumlah penduduk Desa Bongas menurut pekerjaan yaitu sebagai petani dan buruh tani memiliki jumlah yang cukup banyak dibandingkan dengan pekerjaan lainnya yaitu 2,846 orang. Hal tersebut dikarena daerah Bongas sebagian besar lahannya adalah persawahan, sehingga para petani memanfaatkan buruh tani untuk menggarap sawah mereka guna keberlangsungan hidup mereka dari hasil panen yang di dapat. Jadi pada intinya, adalah terjadi simbiosis mutualisme, dimana saling menguntungkan satu sama lain.

3. Sejarah Berdirinya LSM Kusuma Buana

\section{LSM Kusuma}

Buana/Yayasan Kusuma Buana (YKB) adalah lembaga sosial yang berdiri pada tanggal 8 Februari 1980 yang didirikan oleh Dokter Firman
Lubis, MPH yang merupakan salah satu dari 16 NGO's anggota Indonesia Against Child Trafficking (Indonesia ACTs) yang tersebar di 10 propinsi. LSM Kusuma Buana pusat berada di Jl. Asem Baris Raya A/3, Gedang Peluru, Tebet, Jakarta Selatan. YKB memilih Indramayu sebagai tempat berdirinya YKB dalam pencegahan prostitusi anak di bawah umur karena penemuan dilapangan pada program YKB pada tahun 1993 - 1999 di Kramat Tunggak dan ditempat hiburan lain terdapat 90\% PSK (Pekerja Seks Komersial) berasal dari Indramayu, kebanyakan yang menjadi PSK 60\% berpendidikan SD dan bahkan ada yang tidak tamat SD, serta banyaknya perkawinan dan perceraian muda. Dari sini LSM Kusuma Buana membentuk kelompok kerja di Desa Bongas guna pencegahan prostitusi anak dengan nama Kusuma Bongas. 
Peran LSM dalam Pendampingan PSK

LSM Kusuma Buana berdiri di Bongas pada tanggal 23 April tahun 2003 dengan alamat di Desa Bongas, Blok Penanggul, kecamatan Bongas, Kabupaten Indramayu dengan nama Kusuma Bongas yang mempunyai tim di dalamnya yaitu:
a. TOMAS
(Tokoh Masyarakat)/ TOGA (Tokoh Agama)
b. Guru yang komitmen terhadap pengembangan Bongas
c. Mantan Trafiker
d. Mantan TKW

Dengan dukungan stakeholder (sekolah, kepolisian, rumah sakit, puskesmas, tokoh masyarakat dan pemda) dan masyarakat, dengan satu tujuan yaitu "Kepentingan yang terbaik untuk anak serta kemajuan Bongas dan Indramayu". LSM Kusuma Buana yang ada di Desa Bongas merupakan kelompok kerja dari LSM Kusuma Buana pusat akan dilegalkan pada tahun 2011 bulan Juni. LSM Kusuma Buana di Desa Bongas bernama Kusuma Bongas karena letaknya berada di Desa Bongas dan anggota pengurus di dalamnya berasal dari Desa Bongas, sehingga kelompok kerja yang di bentuk LSM Kusuma Buana bernama Kusuma Bongas. Kusuma Bongas merupakan lembaga sosial pertama yang ada di Desa Bongas dalam pendampingan PSK dan mantan PSK (warga dampingan). Program yang di berikan LSM Kusuma Bongas kepada masyarakat di Desa Bongas untuk bisa memberdayakan warga dampingan agar dapat mandiri.
Dana yang diperoleh LSM Kusuma Bongas dalam menjalankan program-programnya dari LSM Kusuma Buana pusat dan pendanaan TDH (Terre Des Hummes) Belanda, dalam mendapatkan dana tersebut Kusuma Bongas melakukan pembuatan proposal yang menjelaskan rincian programprogram yang akan dijalankan oleh LSM Kusuma Bongas.

\section{Peran LSM Buana Dalam Pendampingan PSK di Desa Bongas}

1. Perencanaan Program dan Identifikasi Kebutuhan Koentjaraningrat menyatakan bahwa "adapun segala cara berlaku dari individu-individu untuk memenuhi kewajiban dan untuk mendapatkan hak-hak tadi, merupakan aspek dinamis dari status atau kedudukan". Cara-cara berlaku itu disebut peranan. ${ }^{8}$ Peranan (role) merupakan aspek dinamis kedudukan (status). Apabila seseorang melaksanakan hak dan kewajibannya sesuai dengan kedudukannya maka dia menjalankan suatu peranan. Tak ada peranan tanpa kedudukan atau kedudukan tanpa peranan. Pentingnya peranan adalah karena peranan mengatur perilaku seseorang. Peranan dapat diartikan sebagai dinamisasi dari status atau pun kedudukan seseorang dalam melaksanakan hak-hak dan kewajibannya. Sedangkan status

\footnotetext{
${ }^{8}$ Soleman b. Taneko, SH, Struktur Dan Proses Sosial Suatu PengantarSosiologi Pembangunan, Jakarta: CV. Rajawali, 1984, hal. 88.
} 
dapat diartikan sebagai kedudukan yang memberikan hak dan kewajiban pada seseorang. ${ }^{9}$ Hubungan-hubungan sosial yang ada dalam masyarakat, merupakan hubungan antara peranan-peranan individu dalam masyarakat. Peranan diatur oleh norma-norma yang berlaku. Posisi seseorang dalam masyarakat (social position) merupakan unsur statis yang menunjukkan tempat individu pada organisasi masyarakat. Peranan lebih banyak menunjukkan pada fungsi, penyesuaian diri dan sebagai suatu proses. Peranan mencakup tiga hal, yaitu:

a. Peranan meliputi normanorma yang dihubungkan dengan posisi atau tempat seseorang dalam masyarakat. Peranan dalam arti ini merupakan rangkaian peraturan-peraturan yang membimbing seseorang dalam kehidupan masyarakat.

b. Peranan adalah suatu konsep tentang apa yang dapat dilakukan oleh individu dalam masyarakat sebagai organisasi.

c. Peranan juga dapat dikatakan sebagai perilaku individu yang penting bagi struktur sosial masyarakat. ${ }^{10}$

Peran yang dilakukan oleh Kusuma Buana berupa pendampingan terhadap PSK di Desa Bongas. Pendampingan adalah

\footnotetext{
9 Mayor Polak dalam Siti Irene Astuti D, Pengaruh Peran Ganda Wanita terhadap Konflik Peranan di Dalam Keluarga, Surabaya: FISIPOL UNAIR, 1985, hal. 19.

${ }^{10}$ Soerjono Soekanto, op. cit, hlm 244.
}

pekerjaan sosial yang mempunyai kompetensi profesional dalam bidangnya. Program yang dilakukan oleh para pekerja sosial betujuan untuk membantu permasalahan yang dihadapi PSK. ${ }^{11}$ Peran LSM Kusuma Bongas dalam pendampingan PSK merupakan peranan yang disesuaikan (actual roles) yaitu bagaimana sebenarnya peranan dijalankan. Dimana dalam pelaksanaannya lebih luwes, sehingga dapat disesuaikan dengan situasi dan kondisi yang ada di Desa Bongas.

Peran Kusuma Bongas dalam pendampingan PSK bisa menjadi rumah sementara bagi para PSK, dimana para PSK dibina selama enam bulan dengan diberikan program-program pendampingan untuk membantu permasalahan yang dihadapi oleh para PSK dan memberikan solusi dari permasalahan yang mereka hadapi. Selain itu peran Kusuma Bongas bisa menjadi tempat untuk mencurahkan isi hati para PSK, mengenai apa saja yang dikeluhkan oleh PSK dengan menjadi sahabat bagi para PSK. Peran Kusuma dalam hal ini sangat membantu bagi para dampingan (PSK) untuk lebih bisa mengedalikan diri mereka agar dapat mandiri dan mampu bersosialisasi dengan masyarakat setempat.

Pendampingan yang di lakukan oleh LSM Kusuma Buana melalui pendidikan kemandirian

\footnotetext{
${ }^{11}$ Depsos, Modul/Pembinaan Penanganan Anak Jalanan Untuk Supervisor, Jakarta, 1997, hal. 16.
} 
terhadap PSK dengan berperan sebagai berikut:

a. Fasilitator dan katalisator, yaitu melalui para pembina yang tinggal di tengahtengah kelompok menyertai proses perkembangan kelompok dampingan yaitu PSK, membantu memecahkan masalah dan ikut menentukan alternatif pemecahannya.

Pembina/pengurus LSM

Kusuma Buana memposisikan diri mereka sebagai sahabat bagi PSK dalam proses mencapai dan mengembangkan kemandiriannya.

b. Pelatih dan pendidik, yaitu mencarikan dan menyalurkan informasi dan pengalaman dari luar ke dalam kelompok dampingan yaitu PSK. Informasi dan pengalaman dari luar tersebut terlebih dahulu dipilih dengan melihat situasi dan kondisi, baik di dalam LSM Kusuma Buana mau pun PSK.

c. Pemupuk modal antara lain dengan mendorong upayaupaya penghematan, menabung, dan usaha produktif. LSM Kusuma Bongas bisa berfungsi sementara sebagai lembaga keuangan setempat atau sebagai penghubung dengan lembaga keuangan terdekat. Lembaga keuangan yang dibentuk oleh LSM Kusuma Bongas adalah adanya dana bergulir berupa pinjaman bagi PSK mau pun masyarakat setempat yang kurang mampu. ${ }^{12}$

Perencanaan program yang dilakukan Kusuma Bongas untuk pendampingan PSK, dengan cara melakukan the need for Achievenment yaitu melihat kebutuhan dan dorongan untuk berprestasi dengan lingungannya. Pada tahun 2003 sampai 2004, tim Kusuma Bongas melakukan penelitian untuk mengetahui apa saja yang diperlukan untuk pendampingan terhadap PSK di Desa Bongas. Dilakukannya the need for Ashievement atau n-Ach oleh Kusuma Bongas tujuannya untuk mendidik agar PSK di Desa Bongas dapat merubah sikap yang pasrah menjadi sikap yang berani melawan nasib. Hasil penelitian yang dilakukan oleh tim fasilitator Kusuma Bongas pada tahun 2005 2008 dan 2010 menunjukkan jumlah yang bekerja sebagai PSK, yaitu:

\footnotetext{
12 Onny S. Prijono dan A. M. W. Pranarka, op.cit, hlm. 105.
} 
Tabel : 2

Pemetaan dari tahun 2005, 2006, 2007, 2008, dan 2010

\begin{tabular}{|c|l|c|c|c|c|}
\hline \multirow{2}{*}{ Nama } & \multicolumn{5}{|c|}{ Tahun } \\
\cline { 2 - 6 } & \multicolumn{1}{|c|}{2005} & 2006 & \multicolumn{1}{|c|}{2007} & \multicolumn{1}{|c|}{2008} & 33 \\
\hline \multirow{2}{*}{ PSK } & $\begin{array}{l}63 \\
\text { orang }\end{array}$ & 54 orang & $\begin{array}{l}48 \\
\text { orang }\end{array}$ & $\begin{array}{l}38 \\
\text { orang }\end{array}$ & $\begin{array}{l}33 \\
\text { orang }\end{array}$ \\
\hline
\end{tabular}

(Arsip: Kusuma Bongas dalam Pemetaan terhadap PSK dari tahun 2005 - 2010 di Desa Bongas Kecamatan Bongas Kabupaten Indramayu)

Berdasarkan tabel di atas dapat disimpulkan bahwah jumlah PSK dari tahun ke tahun semakin menurun dengan adanya dampingan terhadap PSK dari pihak Kusuma Bongas. Pada tahun 2009, pihak Kusuma Bongas tidak melalakukan pemetaan, kemudian pada tahun 2010 Kusuma Bongas melakukan pemetaan terhadap PSK di Desa Bongas. Hasilnya menunjukkan jumlah angka PSK di Desa Bongas semakin menurun dengan dilakukannya pemetaan dari tahun ke tahun.

Dari jumlah tersebut pihak LSM Kusuma Bongas melakukan peninjauan kembali yang dikhususkan terhadap PSK di Desa Bongas yang nantinya akan dijadikan dampingan oleh Kusuma Bongas, kemudian diberdayaan melalui program-program yang akan di berikan kepada PSK nantinya. Dari hasil n-Ach ditemukan bahwa PSK membutuhkan pertumbuhan dan dorongan dalam faktor ekonomi dan kemandirian., sehingga Kusuma Bongas membentuk beberapa perencanaan program untuk menangani prostitusi, antara lain:

a. Kegiatan Ketrampilan

b. Layanan Kesehatan c. Pemberdayaan Masyarakat (penyuluhan dan modal bergulir)

Perencanaan program di atas akan dijalankan oleh Kusuma Bongas untuk pendampingan terhadap PSK agar dapat diberdayakan melalui perencanaan program-program tersebut. Adanya perencanaan program di dalam lembaga sosial, memudahkan untuk memantau sejauh mana dampingannya dapat diberdayakan dan mandiri. Seperti halnya dengan Kusuma Bongas, sebelum menjalankan program, dibentuk perencanaan programnya terlebih dahulu, kemudian menjalankan program yang sudah sesuai dengan hasil $n$-Ach. Selain, itu perencanaan program ini merupakan langkah awal yang dibuat oleh tim Kusuma Bongas untuk pendampingan terhadap PSK di Desa Bongas agar bisa mandiri dan diswadayakan melalui program-program yang akan dijalankan oleh Kusuma Bongas.

2. Rekuitment

Perekrutan warga dampingan yang dilakukan oleh pihak Kusuma Bongas melalui rujukan dari LSM Kusuma Buana pusat. Jumlah PSK yang dirujukan oleh LSM Kusuma Buana ada 15 
Peran LSM dalam Pendampingan PSK

orang untuk di berdayakan melalui

Bongas, sebagai berikut:

kelompok kerja bernama Kusuma

Tabel : 3

Jumlah Dampingan (PSK) rujukan dari LSM Kusuma Buana

\begin{tabular}{|c|c|l|}
\hline No & Nama Samaran & \multicolumn{1}{|c|}{ Umur } \\
\hline 1. & Rosi & 17 Tahun \\
\hline 2. & Selvi & 17 Tahun \\
\hline 3. & Dede & 19 Tahun \\
\hline 4. & Eva & 14 Tahun \\
\hline 5. & Marisa & 17 Tahun \\
\hline 6. & Fina & 16 Tahun \\
\hline 7. & Yunita & 19 Tahun \\
\hline 8. & Ani & 17 Tahun \\
\hline 9. & Fera & 21 Tahun \\
\hline 10. & Tina & 28 Tahun \\
\hline 11. & Lusi & 17 Tahun \\
\hline 12. & Nina & 23 Tahun \\
\hline 13. & Yesi & 18 Tahun \\
\hline 14. & Karmila & 17 Tahun \\
\hline 15. & Santi & 20 Tahun \\
\hline
\end{tabular}

(Arsip: Kusuma Bongas, peserta Life Skill)

Berdasarkan tabel di atas menunjukkan jumlah rujukan PSK kepada Kusuma Bongas untuk diperdayakan melalui programprogram pendampingan seperti pemberdayaan masyarakat berupa penyuluhan dan modal bergulir, penyuluhan kesehatan, dan kegiatan ketrampilan, karena asal dari 15 orang PSK tersebut berasal dari Desa Bongas.

Perekrutan untuk masuk atau dapat menjadi dampingan Kusuma Bongas, pihak LSM Kusuma Buana maupun Kusuma Bongas tidak memakai kriteria-kriteria tertentu. Untuk menjadi dampingan diberlakukan bagi kalangan mana pun. Kusuma Bongas dalam merekrut PSK untuk di jadikan dampingannya bekerja sama dengan kader-kader yang dibentuk oleh Kusuma Bongas itu sediri, cara dibentuknya kader-kader tersebut dengan cara mengambil dua orang untuk dijadikan kader dari setiap RT di Desa Bongas. Kader-kader inilah sebagai tangan kanan dari Kusuma Bongas dalam merekrut PSK untuk dijadikan dampingan Kusuma Bongas. Bagi PSK yang sudah menjadi dampingan di berdayakan selama enam bulan lama. Jangka waktu enam bulan tersebut diharapkan PSK mampu mandiri dengan di berikan modal bergulir, berupa disewakan tanah (sawah) untuk dikelola sendiri dan hasil yang didapat untuk sediri serta modal bergulir dalam bentuk 
uang untuk modal usaha bagi para PSK yang menjadi dampingan Kusuma Bongas.

\section{Program Pendampingan}

1. Pemberdayaan Masyarakat (penyuluhan dan modal bergulir)

Pemberdayaan masyarakat yang dilakukan LSM Kusuma Bongas kepada PSK dengan memberikan penyuluhan tentang dampak buruk dari prostitusi dan Trafficking. Pada dasarnya pemberdayaan masyarakat ini ditunjukkan kepada para orang tua agar tidak mempekerjakan anaknya menjadi PSK. Pada kenyataannya pemberdayaan ini bisa diikuti oleh kalangan mana pun, termasuk PSK dan mantan PSK. Tujuan dari program ini untuk memberdayakan penduduk di Desa Bongas baik warga dampingan mau pun penduduk setempat. Peran Kusuma Bongas disini sebagai pelatih dan pendidik, dimana Kusuma Bongas mencarikan dan menyalurkan informasi dan pengalaman dari luar ke dalam kelompok dampingan yaitu PSK. Informasi dan pengalaman dari luar tersebut terlebih dahulu dipilih dengan melihat situasi dan kondisi, baik di dalam LSM Kusuma Bongas mau pun PSK. Selain itu, Kusuma Bongas berperan sebagai pemupuk modal antara lain dengan mendorong upaya-upaya penghematan, menabung, dan usaha produktif. LSM Kusuma Bongas bisa berfungsi sementara sebagai lembaga keuangan setempat atau sebagai penghubung dengan lembaga keuangan terdekat. Lembaga keuangan yang dibentuk oleh LSM Kusuma Bongas adalah adanya modal bergulir berupa pinjaman bagi PSK mau pun masyarakat setempat yang kurang mampu. Modal bergulir ini bisa berbentuk tanah mau pun uang.

2. Layanan Kesehatan

Tujuan utama dari kegiatan ini adalah untuk para PSK/mantan PSK yang terkena AIDS maupun yang tidak terkena HIV/AIDS, kendala yang dihadapi oleh LSM Kusuma Bongas adalah banyak PSK yang terkena penyakit tersebut tidak melaporkan diri tentang penyakitnya kepihak Kusuma Bongas, sehingga Kusuma Bongas mengalami hambatan dalam membantu kesehatan para PSK/mantan PSK yang terkena HIV/ AIDS. Bagi PSK/mantan PSK yang melaporkan diri tentang penyakitnya, kepada pihak Kusuma Bongas, maka Kusuma Bongas akan melakukan rujukkan ke pihak rumah sakit guna mengatasi masalah tersebut, karena rumah sakit maupun puskesmas setempat merupakan stakeholder dalam penanganan masalah HIV/AIDS. Peran Kusuma Bongas dalam layanan ini sebagai fasilitator dan katalisator, yaitu melalui para anggota yang tinggal di tengahtengah kelompok menyertai proses perkembangan kelompok warga dampingan (PSK dan mantan PSK), membantu memecahkan masalah dan ikut menentukan alternatif pemecahannya. Masalah yang ada bahwa HIV/AIDS merupakan dampak buruk bagi warga dampingan di Kusuma Bongas, sehingga alternatif yang dilakukan 
oleh Kusuma Bongas dalam layanan kesehatan mengenai HIV/AIDS dengan cara melakukan rujukan kepada pihak rumah sakit setempat.

3. Kegiatan Ketrampilan

Kegiatan ketrampilan yang di berikan kepada PSK merupakan salah satu program yang sangat baik untuk keberlangsungan PSK di Kusuma Bongas, karena PSK tersebut bisa berlatih dan mengasah skill yang ada di dalam diri mereka. Kegiatan ketrampilan yang diberikan kepada PSK berupa ketrampilan menjahit dan tata boga. Peran Kusuma Bongas dalam kegiatan ketrampilan nini adalag sebagai fasilitator, dimana semua kebutuhan PSK mengenai ketrampilan di fasilitasi. Dalam memberikan ketrampilan terhadap PSK, pihak Kusuma Bongas mengundang para ahli dibidangnya masing-masing.

Dari hasil pemberdayaan ini PSK bisa mendirikan usaha sendiri dari hasil yang mereka dapat saat mengikuti pelatihan ketrampilan yang diadakan oleh Kusuma Bongas. PSK diberdayakan melalui kegiatan ketrampilan tujuannya adalah agar para PSK bisa menuangkan ide kreatif yang mereka miliki dan sebagai pembentuk kemandirian bagi PSK yang menjadi dampingan Kusuma Bongas. Hasil dari ketrampilan yang di buat oleh PSK tersebut, di jual kepada masyarakat setempat dan di dalam Kusuma Bongas itu sendiri, sehingga hasil penjualan dari karya yang mereka buat sendiri sudah sedikit bisa membantu kebutuhan ekonomi mereka.

\section{E. Pemberdayaan/Pendampingan yang dilakukan oleh LSM Kusuma Buana terhadap PSK}

Pemberdayaan adalah sebuah proses dan tujuan. Sebagai proses, pemberdayaan merupakan serangkaian kegiatan memperkuat kekuasaan atau keberdayaan kelompok lemah dalam masyarakat, termasuk individu-individu yang mengalami masalah kemiskinan. Sebagai tujuan, pemberdayaan menunjuk pada keadaan atau hasil yang ingin dicapai oleh sebuah perubahan sosial yaitu masyarakat yang berdaya, memiliki kekuasaan atau mempunyai pengetahuan dan kemampuan dalam memenuhi kebutuhan hidupnya baik yang bersifat fisik, ekonomi, maupun sosial seperti memiliki kepercayaan diri, maupun menyampaikan aspirasi, mempunyai mata pencaharian, berpartisipasi dalam kegiatan sosial, dan mandiri dalam melaksanakan tugas-tugas kehidupannya. Pengertian pemberdayaan sebagai suatu tujuan seringkali digunakan sebagai indicator keberhasilan pemberdayaan sebagai sebuah proses. ${ }^{13}$

Situasi yang kurang mampu dan meningkatnya prestis yang membuat para orangtua di Desa Bongas mempekerjakaan anak gadis mereka untuk bekerja sebagai PSK, selain itu tindakan menyimpang ini

\footnotetext{
${ }^{13}$ Edi Suhartono, op, cit, hal. 59 - 60.
} 
di anggap mereka adalah suatu jalan keluar untuk memenuhi kebutuhan keluarga, dengan demikian anomie adalah suatu keadaan atau nama dari situasi di mana kondisi sosial/situasi masyarakat lebih menekankan pentingnya tujuan-tujuan status, dan penyimpangan ini merupakan cara yang alternatif dalam meraih kesuksesan ekonomi.

Untuk mencegah terjadinya situasi yang kurang mampu tersebut, Kusuma Bongas mempunyai upaya-upaya untuk melakukan pendampingan terhadap PSK dengan melakukan upaya memberdayaan, menurut Kartasasmita, mempunyai upaya untuk memperdayankan dampingan harus dilakukan dengan tiga cara, yaitu: Pertama, menciptakan suasana atau iklim yang memungkinkan potensi dampingan (PSK) untuk berkembang. Kondisi ini berdasarkan asumsi bahwa setiap individu memiliki potensi yang dapat dikembangkan. Kemandirian dan keberdayaan dampingan (PSK) Kusuma Bongas adalah keyakinan bahwa PSK tersebut memiliki potensi untuk mengorganisasikan dirinya sendiri dan potensi kemandirian tiap individu perlu diberdayakan. Kedua, memperkuat potensi atau daya dimiliki oleh PSK berupa dampingan Kusuma Bongas dengan menerapkan langkahlangkah nyata, menampung berbagai masukan, menyidiakan prasarana dan sarana baik fisik mau pun sosial yang dapat diakses oleh masyarakat lapisan bawah. Terbentuknya akses pada berbagai peluang akan membuat PSK makin berdaya, seperti tersedianya lembaga-lembaga pendanan dan pelatihan. Upaya memberdayakan PSK ini yang paling penting adalah peningkatan mutu dan perbaikan sarana dan modal bagi dampingan (PSK) Kusuma Bongas. Ketiga, memberdayakan dampingan dalam arti melindungi dan membela kepentingan dampingan (PSK) yang lemah. Proses pemberdayaan harus dicegah jangan sampai yang lemah bertambah lemah atau makin terpinggirkan dalam menghadapi yang kuat. Perlindungan dan pemihakan kepada yang lemah amat mendasar sifatnya dalam konsep pemberdayaan dampingan (PSK) Kusuma Bongas. ${ }^{14}$

Pemerintah setempat memberikan kontrol kepada masyarakatnya berupa kebijakan Peraturan Daerah (Perda) Nomor 7 Tahun 1999 tentang Prostitusi yang diperbaharui Perda No. 4 Tahun 2001 Perda tersebut memuat 10 pasal, intinya adalah Larangan untuk mendirikan atau mengusahakan serta menyediakan tempat untuk melakukan prostitusi, Sanksi hukuman kurungan baik perempuan maupun laki-laki yang melakukan prostitusi selamalamanya 6 (enam) bulan atau denda sebanyak-banyaknya Rp 5.000.000,(lima juta rupiah). Perubahan Perda berikutnya mengurangi hukuman menjadi selama-lamanya 3 (tiga) bulan, sedangkan denda tetap, dan Pemberian kewenangan kepada Penyidik Umum atau Penyidik PNS

\footnotetext{
${ }^{14}$ Onny S. Prijono dan A. M. W. Pranarka, op.cit, hlm. 105.
} 
Peran LSM dalam Pendampingan PSK

di Lingkungan Pemerintah Daerah. Serta Peraturan Daerah No. 17 Tahun 2002 tentang Renstra Kabupaten Indramayu. Perda ini memasukkan pelacuran sebagai Penyandang Masalah Kesejahteraan Sosial (PMKS) dengan istilah tuna susila.

\section{F. LSM Kusuma Buana dalam Persepri PSK}

Persepsi pada hakikatnya adalah proses kognitif yang dialami oleh setiap orang di dalam memahami informasi tentang lingkungannya, baik lewat penglihatan, pendengaran, penghayatan, perasaan, dan pengalaman ${ }^{15}$. Persepsi menurut Depdiknas adalah suatu tanggapan atau penerimaan langsung dari suatu serapan yaitu proses seseorang mengetahui beberapa hal melalui panca indera ${ }^{16}$.

Persepsi PSK mengenai LSM Kusuma Buana di Desa Bongas, antara lain:

a. Kusuma Bongas sangat membantu dalam hal ekonomi bagi PSK, karena dalam pemberdayaan masyarakat berupa modal bergulir dapat membantu perekonomian meskipun tidak sepenuhnya.

b. Program-program yang diberikan kepada PSK dalam bentuk model pemberdayaan

\footnotetext{
${ }^{15}$ Mifta Toha, Perilaku Organisasi, Jakarta: CV Rajawali, 1983, hlm.138.

16 Depdiknas, Kamus Besar Bahasa Indonesia, Jakarta: Balai Pustaka, hlm. 672.
}

dapat membantuk PSK untuk bisa mandirian dan diswadayaan oleh Kusuma Bongas, selain itu pemberdayaan yang diberikan sudah cukup membantu PSK untuk bisa bersosialisasi dengan masyarakat setempat, karena dengan adanya programprogram yang diberikan sudah membuat PSK bisa hidup berdampingan dengan masyarakat tanpa membedabedakan status sosialnya.

c. Selain pemberdayaan yang di berikan kepada PSK, Kusuma Bongas membuat program untuk pencegahan prostitusi anak di Desa Bongas seperti mendirikan SMP Terbuka dengan tidak mengeluarkan biaya sama sekali bagi anakanak yang kurang mampu, serta memberikan ketrampilan kepada anakanak yang sudah masuk di SMP Terbuka.

\section{G. Simpulan}

Berdasarkan hasil penelitian dan analisis data mengenai peran LSM Kusuma Buana dalam Pendampingan PSK di Desa Bongas dengan memberikan programprogram pendampingan, dapat diambil kesimpulan:

1. LSM Kusuma Buana adalah lembaga sosial yang pertama ada di Desa Bongas dalam pendampingan PSK dengan membentuk kelompok kerja yang 
bernama Kusuma Bongas untuk memberdayakan PSK. Peran Kusuma Bongas Bongas ini berupa pendampingan terhadap PSK. Peran Kusuma Bongas sebagai rumah sementara dan sahabat bagi para PSK yang menjadi dampingan Kusuma Bongas, selain itu pendampingan yang di lakukan oleh LSM Kusuma Buana melalui pendidikan kemandirian bagi PSK dengan berperan sebagai berikut: Pertama, fasilitator dan katalisator, seperti membantu memecahkan masalah dan ikut menentukan alternatif pemecahannya. Kedua, pelatih dan pendidik yaitu mencarikan dan menyalurkan informasi dan pengalaman dari luar ke dalam kelompok dampingan yaitu PSK. Ketiga, pemupuk modal antara lain dengan mendorong upaya-upaya penghematan, menabung, dan usaha produktif. Kusuma Bongas dalam merekrut PSK untuk menjadi dampingannya karena adanya rujukan dari LSM Kusuma Buana pusat untuk diberdayaan. Perekrutan yang dilakukan LSM Kusuma Buana atau pun Kusuma Bongas tidak memberlakukan kriteriakriteria tertentu untuk menjadi dampingan. Bagi siapa pun yang ingin ikut di dalamnya boleh dari kalangan mana pun.

2. Kusuma Bongas memberikan programprogram pendampingan terhadap PSK tujuannya untuk kemandirian dan keswadayaan bagi para PSK yang menjadi dampingan Kusuma Bongas. Programprogram pendampingan yang diberikan kepada PSK, seperti:

a. Pemberdayaan

Masyarakat

(penyuluhan dan modal bergulir)

Pemberdayaan masyarakat yang dilakukan LSM Kusuma Bongas kepada warga dampingannya dengan memberikan

penyuluhan tentang dampak buruk dari prostitusi dan Trafficking. Lembaga keuangan yang dibentuk oleh LSM Kusuma Buana adalah adanya modal bergulir berupa pinjaman bagi warga dampingan mau pun masyarakat setempat yang kurang mampu.

b. Layanan Kesehatan

Tujuan utama dari kegiatan ini adalah untuk para PSK/mantan PSK yang terkena AIDS maupun yang tidak terkena HIV/AIDS. Bagi PSK/mantan PSK yang 
melaporkan diri tentang penyakitnya, kepada pihak Kusuma Bongas, maka Kusuma Bongas akan melakukan rujukkan ke pihak rumah sakit guna mengatasi masalah tersebut, karena rumah sakit mau pun puskesmas setempat merupakan stakeholder dalam penanganan masalah HIV/AIDS yang bekerja sama dengan Kusuma Bongas.

c. Kegiatan Ketrampilan Kegiatan

ketrampilan yang di berikan kepada PSK merupakan salah satu program yang sangat baik untuk keberlangsungan PSK yang menjadi dampingan Kusuma Bongas, karena PSK tersebut bisa berlatih dan mengasah skill yang ada di dalam diri mereka, guna keberlangsungan hidup mereka. Kegiatan ketrampilan yang diberikan kepada PSK berupa ketrampilan menjahit dan tata boga.

3. Persepri PSK terhadap LSM Kusuma Buana atau pun Kusuma Bongas sangat positif, karena dengan adanya Kusuma Bongas yang memberikan programprogram pendampingan, membuat para PSK bisa mandiri dan diberdayakan, serta mampu bersosialisasi dengan masyarakat setempat.

\section{Daftar Pustaka}

Agnes Sunartiningsih. (2004). Pemberdayaan Masyarakat Desa melalui Instansi Lokal. Yogyakarta: Universitas Gadjah Mada.

Asmadi Alsa. 2003. Pendekatan Kualitatif serta Kombinasinya dalam Penelitian Psikologi. Yogyakarta: Pustaka Pelajar Offset.

Drs. Miftah Thoha, MPA. (1983). Perilaku Organisasi. Jakarta: CV. Rajawali.

Edi Suhartono. (2005). Membangun Masyarakat Memperdayakan Masyarakat Kajian Strategis Pembangunan Kesejahteraan Sosial dan Pekerjaan Sosial. Bandung: PT Refika Aditama.

Gunawan Sumodiningrat. (1996). Memberdayakan Masyarakat. Jakarta: Penakencana Nesadwipa, 1996.

Irawan Soenartono. (2002). Metode Penelitian Sosial. Bandung: Remaja Rosdakarya.

J. Dwi Narwoko, dkk. (2007). Sosiologi Teks Pengantar Dan Terapan, Jakarta: Kencana. 
Lexy J. Moleong (2007). Metodologi Penelitian Kualitatif. Bandung: Remaja Rosdakarya.

Mayor Polak dalam Siti Irene Astuti D. (1985). Pengaruh Peran Ganda Wanita terhadap Konflik Peranan di Dalam Keluarga. Surabaya: FISIPOL UNAIR.

Miles Dan Huberman. (1992). Analisis Data Kualitatif. Jakarta: UI Press.

Noeng Muhadjir. (2000). Metodelogi Penelitian Kualitatif. Yogyakarta: Rake Sarasin.

Onny S. Prijono dan A.M.W. Pranarka,(1996). Pemberdayaan Konsep,k Kebijakan dan Implementasi, Jakarta: Center for Strategic and International Studies.

Pemerintahan Kabupaten Indramayu. Surat Mentri Dalam Negeri Republik Indonesia No. 414. 3/316/PMD tanggal 17 Februari 2003 Tentang Sistem Pendataan Profil Desa dan Profil Kelurahan. Diperbanyak oleh Pemerintah Kabupaten Indramayu Dinas Koperasi dan Perdayaan Masyarakat 2006.

Raharjo. (2004). Pengantar Sosiologi Pedesaan Dan Pertanian. Yogyakarta: Gadjah Mada University Press.

Redaksi Sinar Grafika. 2003. Undang-Undang Perlindungan Anank (UU RI No. 23 Tahun 2002). Jakarta : Sinar Grafika
Ritzer, George, dkk. (2004). Teori Sosiologi. Yogyakarta: Kreasi Wacana.

Soerjono Soekanto. (2005). Sosiologi Suatu Pengantar. Jakarta: PT Raja Grafindo Persada.

Soleman b. Taneko, SH. (1984). Struktur dan Proses Sosial Suatu Pengantar Sosiologi Pembangunan. Jakarta: CV. Rajawali.

Sugiyanto. (2002). Lembaga Sosial. Yogyakarta: Global Pustaka Utama.

Suparjan dan Hempri Suyatna. (2003). Pengembangan Masyarakat. Yogyakarta: Aditya Media.

Sofyan S. Willis. (2005). Remaja dan Masalahnya. Bandung: Alfabeta.

Tim Penyusun Kamus. (1994). Kamus Besar Bahasa Indonesia. Jakarta: Balai Pustaka.

\section{Skripsi:}

Tri. (2009). Peranan Lembaga Pemberdayaan Masyarakat Desa dalam Merealisasikan Alokasi Dana Desa untuk Pemberdayaan Masyarakat (studi kasus di Desa Jatiayu, Kecamatan Karangmojo, Kabupaten Gunungkidul). Mahasiswa SI : Universitas Negeri Yogyakarta.

Riski Emaniar. (2010). Peranan Yayasan Indriya Nati Dalam Memberikan Program Pendampingan Bagi Anak Jalanan Perempuan yang Mengalami Tindakan Kekerasan Di Yogyakarta. Mahasiswa SI : Universitas Negeri Yogyakarta. 
| Peran LSM dalam Pendampingan PSK

Internet:

Kantor Kebudayaan dan Pariwisata

http://www.indramayucity.co.cc/i

Kabupaten Indramayu, Kata Kunci:

Sekilas Kota Indramayu, 2008,

ndex.php?p=1_5_Sekilas-Kota-

Indramayu. 21 Maret 2010. Pukul

Tersedia pada 11.40 WIB.

DIMENSIA, Volume 6, No. 1, Maret 2012 | 51 
| Erllyn Nurdiansyah

DIMENSIA, Volume 6, No. 1, Maret 2012 | 52 